\title{
La consagración del escritor Pablo Montoya Campuzano. Un acercamiento a la institución literaria en Colombia*
}

Fecha de recepción: 10 de Enero de 2018

Fecha de aprobación: 15 de mayo de 2018

\section{Resumen}

El primer cuarto del siglo XXI presenta nuevas dinámicas literarias vinculadas a los procesos de consagración de un autor ante la escalada de las grandes editoriales. A partir de lo anterior, se hace necesario entender cómo el autor sigue luchando por establecer su ideología dentro de un sistema que exige estructuras específicas para la producción de pensamiento, imaginación y publicaciones. Para tal efecto, se tomará en cuenta la teoría de Jacques Dubois, con el fin de identificar, de forma práctica, los agentes e instancias dentro de la institución literaria colombiana que intervienen en el proceso de consagración del escritor Pablo Montoya, y la incidencia de los premios literarios que le han otorgado.

Palabras clave: literatura; institución literaria; consagración; literatura colombiana; premios literarios.

Citar: Mahecha Arias, J. (enero-junio de 2018). La consagración del escritor Pablo Montoya Campuzano. Un acercamiento a la institución literaria en Colombia. $L a$ Palabra,(32), 201-218. doi: https://doi.org/10.19053/01218530.n32.2018.8174.

\section{Jacqueline Mahecha Arias}

Licenciada en Español y Filología clásica, Universidad Nacional de Colombia. Magíster en Literatura UPTC Tunja. Docente de la Facultad de Educación. Universidad Santo Tomás. VUAD Villavicencio.

Docente de Español y Literatura de secundaria en el colegio Espíritu Santo de Villavicencio. jmahechaa@gmail.com

* El presente artículo forma parte de la investigación realizada para la tesis "La consagración del escritor. Una aproximación a la institución literaria del siglo XXI. El caso de Pablo Montoya Campuzano", para optar por el título de Magíster en Literatura de la UPTC de Tunja. 


\section{la palabra}

\section{The Consecration of the Writer Pablo Montoya Campuzano. A Glance at the Colombian Literary Institution}

\section{Abstract}

The first quarter of the XXIst century presents new literary dynamics linked to author consecration processes in the context of the boom of large publishing houses. In view of the above, it is necessary to understand how an author continues to struggle in order to establish his or her ideology within a system that requires specific structures for the production of thought, imagination and publications. For this purpose, we will use the theory of Jacques Dubois in order to identify the practical agents and instances within the Colombian literary institution involved in the consecration process of the writer Pablo Montoya, and the incidence of literary prizes that he has received.

Key words: Literature; Literary institution; Consecration; Colombian literature; Literary prizes.

\section{La consécration de l'écrivain Pablo Montoya Campuzano. Une approche de l'institution littéraire en Colombie}

\section{Résumé}

La première partie du XXIème siècle présente de nouvelles dynamiques littéraires liées aux processus de consécration d'un auteur face á l'escalade des grandes maisons d'édition. Ainsi, nous analyserons de quelle manière l'auteur lutte pour établir son idéologie dans un système qui exige des structures spécifiques pour la production de la pensée, de l'imagination et des publications. Nous utiliserons la théorie de Jacques Dubois áfin d' identifier de manière pratique les agents et les instances de l'institution littéraire colombienne qui interviennent dans le processus de consécration de l' écrivain Pablo Montoya et les répercussions des prix littéraires qui lui ont décernés.

Mots-clés: littérature; institution littéraire; consécration; littérature colombienne; prix littéraires. 
¿Qué significa pintar? ¿Qué significa ser asesinado? ¿Qué significa la muerte violenta y qué la representación de esa muerte? ¿Cómo aproximar los derramamientos de la sangre a nuestro diario vivir y hacer que ellos vulneren nuestra comodidad? En el fondo de mi hay algo que se niega a aceptar que un grabado logre expresar la cabal dimensión de un acontecimiento. La realidad siempre será más atroz y más sublime que sus diversas formas de mostrarla. Creo que todo intento de reproducir lo pasado está de antemano condenado al fracaso porque solo nos encargamos de plasmar vestigios, de iluminar sombras, de armar pedazos de vidas y muertes que ya fueron y cuya esencia es inasible. La belleza y siempre he ido tras ella así sea terrible y asquerosa, asi sea nefasta y condenable así sea desmoralizadora y desvergonzada no es más que un conjunto de fragmentos dispersos en telas en letras, en piedras, en sonidos que tratamos de configurar en vano.

Pablo Montoya

En el primer cuarto del siglo XXI, la publicación de obras y aparición de nuevos creadores literarios induce a pensar en los mecanismos de consagración vigentes dentro de la institución literaria colombiana, desde los que provienen del polo de gran producción y que otorgan fama (el top de ventas, la aparición en medios masivos de comunicación), hasta los considerados institucionales, provenientes más del ámbito académico, y que otorgan prestigio, reputación propiamente literaria (homenajes, reconocimientos de universidades, premios, crítica literaria especializada). Teniendo en cuenta lo anterior, el presente artículo analiza las relaciones e instancias de legitimación literaria que se establecen dentro del campo literario colombiano para otorgar la consagración del autor Pablo José Montoya Campuzano, a la vez, reflexionando acerca de la función de la literatura colombiana como institución y de su recepción en los pares lectores del momento.

\section{Trayectoria social y literaria}

\section{Emergencia}

La escritura literaria parte de la creación individual, sin embargo, según Dubois (2014) "todo texto se compone a partir de una tradición y una norma, de suerte que ésta termina por reproducir un gran texto" (p. 70). Al observar la sociedad y las maneras en que circula el capital simbólico, es poco probable preservar ese carácter de individualidad, ya que la institución reconoce que el producto literario "se constituye a partir de varias instancias" (p. 70).

El escritor se ve condicionado durante su trayectoria por varias instituciones sociales: la primera es la familia, después sigue el colegio; estas infunden y transmiten códigos sociales, clasificadores, a través de objetos como la biblioteca familiar o los libros frecuentados en la infancia, que se convierten en un espacio material en donde pueden clasificarse y seleccionarse obras, motivando la elaboración personal de un sistema jerárquico de autores literarios que condicionará, luego, el programa ético y estético del escritor en el campo literario.

El escritor Pablo Montoya Campuzano nació en Barrancabermeja en 1963. Es el noveno de once hijos, de padres antioqueños; su padre, José de Jesús Montoya, nació en Copacabana; y su madre, Mariana Campuzano, en Yolombó. Cuatro años después de su nacimiento, su familia regresó a Medellín, lugar del que huyeron tiempo atrás por el fenómeno de la violencia. Allí, Pablo fue a la escuela pública Juan María Céspedes para hacer su primaria, realizó los estudios secundarios en el Liceo Antioqueño del cual recibió una Beca por ser el mejor bachiller. Ingresa a la carrera de Medicina en la Universidad de Antioquia como una forma de complacer 
a su padre (médico); cursó cuatro semestres y aprendió a tocar la flauta. Luego, se separó de la medicina y decidió profundizar sus estudios musicales en Tunja, hecho que determinó alejarse de su familia. Como músico, llegó a conformar varias orquestas sinfónicas en Colombia. En ese mismo periodo, estudió Filosofía y Letras en modalidad a distancia en la Universidad Santo Tomás, durante el periodo 1987 a 1993; así, obtuvo su título de pregrado. A los treinta años de edad, Pablo decidió emprender un viaje hacia Rusia con el propósito de seguir en la música, pero, por azares del destino, llegó a Francia, y como inmigrante latino interpretó flauta en el metro y sobrevivió desempeñándose además en diversos oficios, entre ellos, dictar clases de español.

Realizó una Maestría en la Universidad Le Sorbonne-Nouvelle, Paris III, entre 1993 y 1995; y el doctorado, de 1996 a 2001, en la línea de Estudios Hispanoamericanos y Latinoamericanos. Acontecimientos que restablecieron su contacto con la Academia. Durante este periodo de crecimiento personal y profesional, formación e investigación, se fortalece su curiosidad por producir obras de carácter histórico y de viajes.

En su niñez, el contacto con la literatura fue a través de su madre, quien tuvo gran fascinación por ella, y le enseñó el gusto por la lectura con libros como las fábulas de Rafael Pombo y los cuentos de Hans Christian Andersen, e historias como la Leyenda de San Julián el hospitalario o Un corazón sencillo, de Gustav Flaubert, que conformaron la colección Ariel Juvenil Ilustrada. Durante su juventud, su encuentro fue con escritores como Herman Hesse y Albert Camus. Las diferentes etapas en la vida de Pablo, han estado acompañadas además de autores que han marcado su estilo literario, como: Margarite Yourcenar, Alejo Carpentier, Julio Cortázar, Juan Rulfo, los poetas latinos, entre ellos, el protagonista de Lejos de Roma, Ovidio, entre otros. Pablo Montoya es un gran lector, por eso tuvo interés en textos revolucionarios, tesis filosóficas y religiosas. Lee a los autores colombianos de diferentes épocas y a sus contemporáneos del siglo XX, como a García Márquez, Álvaro Mutis, Germán Espinosa, Fernando Vallejo, Héctor Abad Faciolince, Piedad Bonnett, Juan Manuel Roca, Jorge Franco. En el ámbito social, en la breve temporada dentro de la ideología de izquierda, hizo algunos coqueteos con el EPL haciendo pintas, pero decide retirarse del proceso. Este episodio lo tendrá en cuenta para su novela Los derrotados, que refleja esos oficios y esas pasiones. El personaje del botánico escritor, puede considerarse el alter ego del escritor, al igual que el fo- tógrafo, según lo manifiesta el mismo Pablo.

El perfil de escritor aficionado, el paso por la medicina, su estatuto de estudiante de educación pública, la música en Tunja y su posterior viaje a Francia, configuran en Pablo José Montoya Campuzano un prisma ideológico para su posterior producción literaria. El intercambio cultural, su estadía en Francia entre 1993 y 2012, y la visita a diferentes ciudades europeas, marcaron los pasos del escritor, $\mathrm{y}$ aunque en sus intervenciones no se percibe la historia del "buen salvaje", sus inquietudes literarias nacionales y extranjeras, y su pasión por la escritura; determinan, de manera categórica, su formación y producción literarias. No en vano compuso sus textos desde la posición de escritor inmigrante con mensajes divergentes. Estableció contacto con diferentes revistas que publicaron sus escritos, cuenta con más de cuarenta artículos hasta el momento, en revistas especializadas, incursionando de esta manera en el mercado de bienes culturales. Los artículos que escribe son, en su gran mayoría, crítica de la literatura colombiana (sobre autores como Gabriel García Márquez, Álvaro Mutis, William Ospina, Mario Escobar Velásquez, entre otros) o sobre la relación de la literatura y la violencia. Por otro lado, retoma a los escritores colombianos que no fueron tan visibles (como Roberto Burgos 
Cantor, por ejemplo), pero tienen una trayectoria académica y poseen un valor estético en las diferentes obras que publican.

En esta fase de emergencia, el escritor Pablo Montoya elabora una parte de su obra sin mantener relaciones con los círculos literarios parisinos, sin embargo, consolida una formación literaria en Francia en una segunda lengua como inmigrante latino. Evidentemente, su vida en Francia estuvo acompañada de la austeridad; vivió allí con su familia, su esposa y su primera hija. Sin embargo, el posicionamiento en la institución literaria no le corresponderá en Francia, sino en Colombia. Durante su estadía, publica: Cuentos de Niquía (París: Vericuetos, 1996), obra bilingüe en castellano-francés, y Habitantes (París: Índigo, 1999); artículos y ensayos que se encuentran en revistas colombianas y extranjeras, además de la publicación de dos de sus obras de cuentos y una en poesía en Colombia entre 1997 y 2003: La sinfónica y otros cuentos musicales (El propio bolsillo, Medellín, 1997), Viajeros (Universidad de Antioquia, Medellín, 1999), Razia (Eafit, Medellín, 2001).

De esta manera, Pablo se inscribió en una literatura minoritaria, provista de originalidad, privilegiando, desde la distancia, la adquisición de capital simbólico, por encima del económico o social (de los que carecía).
El involucrar elementos como la música, la pintura y la fotografía en sus obras, alimenta esa herencia cultural con la diversidad temática en medio de una escena solitaria y apartada de un círculo de amigos escritores, y le permiten cargar de valor literario sus escritos. A propósito de esa relación con la literatura, dirá Montoya: "Por la literatura yo siento un gran cariño, un gran amor. Encuentro en los libros compañía, consuelo, un permanente entusiasmo, siento que los libros avivan profundamente mi curiosidad por la vida, el pasado, el presente y las posibilidades del futuro" (Montoya, entrevistado por Vergara, 18 de febrero de 2016).

La relación interior que tienen la música y la literatura en las obras de Pablo Montoya, se encuentra en su libro La sinfónica y otros cuentos musicales (1997), en el cuento "Madrigal" que fue el ganador del Premio Germán Vargas de la Fundación Alejo Carpentier y el periódico El Tiempo; Programa de mano (2014), prosa poética, dedicado a compositores de la 'música clásica', en él hace un recorrido desde Venantius Fortunatos, himnodista y poeta latino del siglo VI, pasando por Enrique Granados, compositor y pianista español del siglo XIX, hasta llegar a Leo Brower, compositor, guitarrista y director de orquesta cubano del siglo XX. Otras referencias sobre esta relación se encuentran en su libro de ensayos Música de pájaros (2005), el trabajo de la maestría con su investigación Aproximaciones a la música de El perseguidor (1995); y luego, seguirá siendo la música un tema en la tesis doctoral La música en la obra de Alejo Carpentier (2001).

Por otra parte, el arte y la fotografía se presentan de forma clara en su obra Tríptico de la Infamia (2014), relación que despertó interés en Montoya desde 1995 al encontrar tres artistas del siglo XVI; ellos fueron tema de investigación por más de 15 años, favoreciendo el proceso de maduración de su obra, una constante en la obra de Montoya, personajes relacionados con las artes:

Antes de Tríptico de la infamia había escrito otra novela que se llama Los derrotados, que es muy parecida a Tríptico de la infamia porque también aborda unos procesos de violencia, de masacres y de guerra, pero a través de otras disciplinas, de la fotografía y de la botánica. Es como profundizar en esas raíces nuestras y sobre todo, en esas relaciones entre intelectuales, artistas y militancia revolucionaria, donde todo termina atacando al arte. Los derrotados son los artistas, los intelectuales, Los que ganan son los guerreros. Hay entonces una continuidad entre esa novela y Tríptico de la infamia, solo que Los derrotados es sobre Colombia en 
particular, sobre sus procesos de independencia (Carrizosa, 21 de mayo de 2016).

Su labor educativa y su producción ensayística, abrieron un camino en la institución literaria que se puede observar a través de su participación en diferentes instituciones de carácter nacional: Red Nacional de Escritores RENATA (2008), coordinador de los Premios Nacionales de Cultura (2006-2012), coordinador del Doctorado en Literatura de la Universidad de Antioquia (2005-2009), miembro del consejo editorial de la Revista Universidad de Antioquia (2004-2009), profesor e investigador de la literatura vinculado a la misma universidad desde el 2002 y profesor invitado de literatura latinoamericana en las universidades de la Sorbonne Novelle-Paris 3 (2011) y la Universidad Mar de Plata de Argentina (2011). Esta participación le permite establecer relaciones con otros agentes de la institución literaria en Colombia y fuera de ella.

Este proceso de emergencia 1leva implícito "la manera como el autor define su originalidad respecto de otros autores ya sean del pasado o del presente" (Zapata, 2011), es decir, la manera como se presenta la oposición al movimiento literario establecido que tiene acumulado capital simbólico, ya que beneficia al escritor o al grupo de escritores emergente. Pablo Montoya en la etapa de emergencia, buscó posicionarse con nuevas propuestas literarias: por un lado, con un tipo de literatura "erudita" para cierto grupo reducido de lectores (en contraste explícito $\mathrm{y}$ directo frente a las masas que frecuentan otro tipo de narrativa); y por otro, en la relación del autor con la temática que presenta, ya que toma distancia de la cotidianidad para referirse a hechos del pasado histórico de Colombia exaltando el tema de la violencia desde la época de la Conquista alejándose de la lectura directa que hacen los escritores del momento frente a los fenómenos de las guerrillas, el paramilitarismo y el narcotráfico en la primera década del siglo XXI.

De igual manera, la relación de Montoya con las editoriales tiene algunas aristas. En un comienzo, sus primeros libros fueron cuentos publicados con el propio bolsillo y en asociación con un grupo de escritores latinoamericanos emergentes que lograron encontrarse en $\mathrm{Pa}-$ rís. Posteriormente, en el 2002, regresa a Colombia y distribuye su libro Lejos de Roma, en editoriales como Norma, Planeta, Tusquets, Alfaguara y algunas editoriales de Argentina, pero fue rechazada; finalmente, la acepta la editorial Alfaguara y la publica en el 2008. Montoya envía sus posteriores originales a Alfaguara, pero sin una explicación directa eran rechazados, esto debido al desconocimiento de la política editorial que consistía entonces en retirar a un autor si sus libros no se vendían en un periodo de seis meses. Esta realidad editorial comercial le lleva a Montoya con la Editorial independiente Sílaba, que publica sus libros Los derrotados en el 2012 y Lejos de Roma en el 2014, siendo Los derrotados uno de los más vendidos por la editorial, según lo afirma su editora Lucía Donadío, quien comentó sobre la responsabilidad y la experiencia de publicar a escritores como Pablo:

Trabajar con estos autores que no hacen parte del gran mercado editorial es también una forma de apoyar la cultura, de ejercer una resistencia social y un voto de confianza en obras cuyo valor estético está por encima de cualquier asunto comercial. Estos libros revelan muchas aristas de nuestro mundo que se expresan a través de la literatura, el periodismo y el ensayo" [...]. Sobre Los derrotados, de Pablo Montoya, hay que decir que es un libro que llegó a nuestras manos casi limpio. Pablo es muy cuidadoso en su oficio. Quizá es precisamente ese tiempo en que aparentemente estuvo en la sombra él que le favoreció para refinar su creación estética en sus obras, factores que continúan siendo fundamentales en sus publicaciones (Donadío, entrevista en Castaño Guzmán, 06 de enero de 2017). 
Los libros de cuentos El beso de la noche y Adiós a los próceres, los aceptó Conrado Zuluaga, editor de la editorial Panamericana, en el año 2010; de él afirma Montoya: "Creyó en mis escritos y decidió publicarlos" (Montoya, entrevista en Detectives Salvajes, 05 de julio de 2016). El beso de la noche lo publica también Alberto Ramírez en Random House en el mismo año, pero no publica $L o s$ derrotados por el registro de ventas tan bajo. Vuelve a Sílaba y reedita estos tres libros. Incluso pensó en editar allí Tríptico de la Infamia, pero en un encuentro con Gabriel Iriarte, editor de Random House, este le apuesta al texto y lo publica en el 2014.

\section{Reconocimiento}

Pablo decidió dejar la medicina y la música para enfocar todo su proceso creativo en la literatura: "Publiqué mis primeros cuentos en periódicos y revistas, gané mis primeros concursos literarios. Eso me motivó a decidirme por la escritura. Imitaba a los autores que me gustaba" (Montoya, 05 de agosto de 2015). Conociendo el funcionamiento de las instancias de legitimación que podían adjudicar poder simbólico a su figura $\mathrm{y}$ a su obra, encauzar su objetivo de obtener una posición reconocida dentro del campo literario, y optando por una toma de posición que le otorgara autonomía, asumió un esquema de representación simbólico que atendiera a temas contundentes dentro de la sociedad colombiana pero que además estuviera soportado en una producción estética altamente elaborada, desde el punto de vista literario. El proceso de reconocimiento de Pablo fue lento, en una forma de crescendo, afianzándose mediante la continua búsqueda de oportunidad para ser publicado en periódicos, su insistencia en enviar sus escritos a diferentes revistas académicas y editoriales, y concursos. A la vez, buscaba compaginar sus temáticas con modelos clásicos y aprovechar la diversidad de géneros literarios como poema, ensayo, cuento, novela y crítica.

Las instancias de que cumplieron una función determinante en la etapa de reconocimiento de este autor, le permitieron legitimar un discurso autónomo ${ }^{1}$. Los premios obtenidos fueron de carácter académico o de instituciones oficiales de carácter nacional y cultural. Pa- blo Montoya, con veinte años de edad, comienza a ganar reconocimientos literarios en los diferentes premios de cuento y convocatorias de investigación literaria, estos son: Premio nacional de cuento en 1993 "Germán Vargas", Premio Autores Antioqueños en el año 2000, Premio en modalidad de cuento Alcaldía de Medellín 2005, Beca de Creación Alcaldía de Medellín en cuento 2007, Beca de investigación literaria Ministerio de cultura 2008, Beca de creación literaria Alcaldía de Medellín en Novela 2012. Los reconocimientos otorgados por entidades oficiales ${ }^{2}$ afianzan su legitimación como autor dentro de la institución literaria colombiana, además de reafirmar su proceso de autonomía (cuidado de lo estético y no de la búsqueda de una fama de índole comercial o económica). Desde 2012, Montoya eligió la editorial Sílaba (Medellín), de carácter independiente, como su casa de publicación, para no vincularse a las grandes editoriales centradas en la literatura más comercial.

El proceso de reconocimiento de un escritor en Colombia, que en la actualidad tiene cerca de 25 concursos literarios ${ }^{3}$,

\footnotetext{
Para Dubois (2014), "cada una de las instancias puede representarse de manera esquemática, a partir de la jurisdicción que ejerce en un momento preciso de la trayectoria que le permite la entrada de una obra en la historia" (p.74), de modo que los premios funcionan como una acumulación progresiva de legitimación.

2 Los premios literarios y becas de investigación de carácter oficial tuvieron mayor presencia en el ámbito nacional a partir del Premio Nobel otorgado a Gabriel García Márquez, con una convocatoria más abierta a escritores de diferentes condiciones socio-económicas.

3 Según la página web Macondo Literario http://macondoliterario.blogspot.com.co/2017/02/premios-literario- en-colombia-2017.html, Premios Literarios en Colombia para el 2017, dónde se encuentran organizados por.
} 
permite conocer nuevas voces en el ámbito nacional, pero con frecuencia deja en el anonimato a varios escritores. Para el caso de Pablo, comienza su reconocimiento en el ámbito regional, para luego abrirse al panorama nacional presentándose en diferentes categorías de concursos y convocatorias.

No solo en la creación literaria figura Montoya, también en la crítica literaria al publicar su ensayo La novela histórica en Colombia, 1988-2008: entre la pompa y el fracaso en el año 2009, haciendo una valoración crítica de las diferentes obras publicadas en un periodo de veinte años para presentar las tendencias dominantes como los temas de la Conquista, la Colonia y el siglo XIX, en su gran mayoría. Para esa época, también publicó Pablo Montoya La sed del ojo (2004) y otras novelas históricas. Entre las novelas que figuran en su ensayo, se encuentran obras de autores consagrados como $\mathrm{El}$ general en su laberinto (1989) de Gabriel García Márquez y Sinfonía desde el Nuevo Mundo (1990) de Germán Espinosa, La ceiba de la memoria (2007) de Roberto Burgos Cantor, sin olvidarse de novelas que son promocionadas por grandes editoriales y otras publicadas por universidades o editoriales independientes. Este ensayo abrió de alguna manera un espacio de "polémica crítica" como los señalan algunos artículos que se escribieron al respecto, que, finalmente, agradecen por el espacio que abre para la discusión en crítica literaria en Colombia:

Colombia ha tenido excelentes críticos como Baldomero Sanín Cano, Ernesto Volkening, Hernando Valencia Goelkel, Antonio Curcio Altamar, Rafael Gutiérrez Girardot, R. H. Moreno Durán y Álvaro Pineda Botero, para sólo mencionar algunos, pero la frivolidad del medio ambiente cultural reciente ha llevado al olvido sus aproximaciones, dejando el espacio al protagonismo propagandístico de las editoriales multinacionales que inflan a dos o tres nombres $\mathrm{y}$ arrasan como un blitzkrieg alemán con toda la otra producción de los escritores colombianos. Por otro lado, casi solitarios y quijotescos, los críticos jóvenes actuales deben ceñirse a los espacios cada vez más escasos para el análisis y sus trabajos se pierden con rapidez en las hojas amarillentas de los periódicos, los sitios internet $\mathrm{o}$ las revistas confidenciales, al carecer Colombia, a diferencia de México, de la tradición de recopilar en volúmenes las notas de esos entusiastas y marginales comentaristas nuestros de las últimas décadas, que sería útil para ver claro entre la maraña.

Por esta razón, el nuevo libro de Pablo Montoya es saludable porque se trata de un trabajo de largo aliento, serio, mesurado, argumentado, jus- to, erudito, donde el autor, sin amiguismos y haciendo gala de su amplia formación académica y su larga experiencia intelectual y vital en Europa, dialoga sin contemplaciones ni zalamerías con todas esas obras que muestran la vitalidad creativa colombiana del post- macondismo. (García, en Montoya, Pablo Montoya [Página web]).

El discurso literario de Pablo Montoya frente a la crítica, es reconocido entonces por otro metadiscurso. Esta relación entre autor de crítica y lector crítico se consolida, en un momento en que los críticos literarios colombianos no iban más allá de Baldomero Sanín Cano, Rafael Gutiérrez Girardot, Hernando Téllez y R.H. Moreno Durán. El espacio para la polémica que abre Montoya frente a la crítica colombiana, constituye los mecanismos de reconocimiento, por medio de los cuales comienza a sentirse la voz de un autor que pone en la palestra las obras publicadas de autores que fueron aplaudidas por sus pares; lo anterior se puede observar en artículos como "Tomás carrasquilla y los críticos colombianos del siglo XX" (2008), publicado Revista de la Estudios de Literatura Colombiana de la Universidad de Antioquia; "Fernando Vallejo: Demoliciones de un reaccionario" (2007), publicado en las revista Número; "Contornos de la crítica literaria en Colombia", publicado en la Revista Literatura: Teoría, 
Historia, Crítica de la Universidad Nacional de Colombia y "La representación de la violencia en la reciente literatura colombiana" (2000), publicado en la revista América Cahiers Du Criccla en Francia.

\section{Consagración}

En el caso de la consagración de Pablo Montoya en el campo literario, ocurren varias cosas que llaman la atención. La primera es que los espacios literarios que lo consagran no son editoriales, aunque es innegable que la publicación de Tríptico de la infamia con Random House, es inseparable del premio otorgado por el gobierno venezolano, pues fue la editorial la que envió la novela al concurso. La segunda, es que sus obras no están enmarcadas en los temas de actualidad que aborda la mayoría de los autores colombianos. Y la tercera es su estilo particular de articular música, pintura, fotografía y literatura. Estos aspectos aportan el carácter de construcción de una obra y de una trayectoria literaria autónoma, es decir, sin dependencias (en demasía) del sector de gran producción o de producción comercial del campo literario.

La consagración de Pablo José Montoya Campuzano llega con el Premio Internacional de novela Rómulo Gallegos 2015 por su obra Tríptico de la infamia. El Premio Rómulo Gallegos lo organiza el CELARG (Centro de Estudios Latinoamericanos Rómulo Gallegos); fue creado en honor al gran novelista y político venezolano que vivió entre 1884 y 1969 , el 6 de agosto de 1964. Es considerado uno de los galardones más prestigiosos de la literatura hispanoamericana. En un comienzo fue cada cinco años, pero desde 1987 es bienal. El jurado estuvo conformado en un comienzo por 13 escritores con una trayectoria consolidada, pero con el pasar de los años se fue reduciendo hasta quedar en tres jurados, incluido el ganador del año anterior. Para el 2015, estuvo conformado por la venezolana María Libertad Suárez, el ecuatoriano Javier Váscones y el puertorriqueño Eduardo Lalo (Ganador del Premio en el año 2014), quienes eligieron Tríptico de la infamia como 'el mejor libro de habla castellana de 2015' dentro de 162 obras de 17 países; según la información de los jurados, se presentaron 60 novelas colombianas (entre ellas, una de Piedad Bonnett y otra deH. Abad Faciolince, ambas finalistas en el concurso). Otros finalistas fueron el costarricense Carlos Cortés con el libro Larga noche hacia mi madre, la chilena Diamela Eltit, con su novela Fuerzas especiales y el mexicano Dante Medina con Amor, cuídate de mí, escritores con reconocidos en su país por sus obras, estilo, trayectoria académica y formación (en el exterior).
Durante estos 53 años de existencia, han ganado cinco colombianos el premio Rómulo Gallegos: en 1972, Gabriel García Márquez con su obra Cien años de soledad; en 1989, Manuel Mejía Vallejo con su obra La casa de las dos palmas; en el 2003, Fernando Vallejo con su obra El desbarrancadero; en el 2009, William Ospina con su obra El país de la canela; y en el 2015, Pablo Montoya con su obra Tríptico de la Infamia, una novela histórica en la cual mezcla narradores y géneros literarios, y predomina el tono poético; de allí que, el autor insista en la importancia del proceso de metaforización que contiene su obra. Un autor maduro en su escritura, con veinte obras publicadas, a quien la calidad literaria, creatividad y la diversificación de géneros le han interesado. La escritura de Tríptico de la infamia comienza con la Beca de creación que ganó de la Alcaldía de Medellín en 2012; luego, una beca en Alemania que le permitió investigar en algunas ciudades de Europa; para finalmente, ser publicada en el 2015 por la editorial Random House. Gabriel Iriarte, el editor, fue un gran apoyo para Pablo, ya que debido al interés que mostró en su libro, se dio su posterior publicación en esta editorial reconocida, permitiéndole llegar a otros públicos.

En el año siguiente, 2016, a sus 56 años recibió otro reconocimiento literario al ganarse 
el Premio Iberoamericano de Letras José Donoso (por toda su obra). Este premio es otorgado por la Universidad de Talca en Chile desde el año 2001 a la obra de un escritor en habla hispana y portuguesa con reconocimientos dentro de la literatura. Es entregado en la Feria del Libro de Talca cada año por un jurado internacional conformado por un grupo de seis académicos y literatos de gran trayectoria literaria; en el 2016, este grupo estuvo conformado por: Horst Nitschack, académico de la U. de Chile, quien presidió el jurado; Diana Kinger, de la U. Federal Fluminense de Brasil; Mónica Marinone, de la U. Nacional de la Plata, Argentina; Rory O'Bryen, de la U. de Cambridge, de Reino Unido; y Raquel Arias, de la U. Autónoma de Madrid, España. Pablo es el primer colombiano en ganar este galardón; también lo han recibido José Emilio Pacheco, Isabel Allende, Ricardo Piglia, Javier Marías y Juan Villoro. Los jurados de este reconocimiento concluyeron lo siguiente respecto al escritor y su obra:

Tiene un carácter disruptivo e innovador que no solo se desvía de las corrientes de la literatura colombiana de las últimas dos décadas, sino que también ensancha el imaginario latinoamericano al incorporar historias y tradi- ciones estéticas y vivenciales opacadas por las exigencias del mercado cultural. [...] Es un maestro de la frase corta, y de la descripción de sensaciones y emociones. En la traza de las grandes figuras de la escritura de América Latina, nutre su tratamiento de temas nacionales con un generoso universalismo. Su escritura combina una deslumbrante erudición con un lenguaje depurado que establece complicidades con el lector. (Nitschack, en Utalca.cl, 02 de septiembre de 2016).

Un tercer momento que acompaña la consagración de Pablo Montoya, es el Premio José María Arguedas también en el 2016, este premio, que desde el año 2000, Casa de las Américas convoca con una frecuencia anual en homenaje al escritor peruano que conformó el grupo de Casa de las Américas, con el fin de difundir literatura relevante denominada por la Casa como los 'clásicos de hoy'. El jurado estuvo conformado por Rey Andújar (República Dominicana), Juan Cárdenas (Colombia), Ana García Bergua (México), Ahmel Echeverría (Cuba). Este premio según Montoya le honra, pues Arguedas es un autor a quien admira profundamente; recuerda de él la novela $L O S$ ríos profundos (1958). Este premio otorgado a su obra
Tríptico de la infamia, tiene el siguiente concepto del jurado: "Construye una fascinante, peculiar y polifónica historia de los tiempos de la conquista de América, y algunos de los singulares personajes que tomaron parte de ella con una prosa cuidada y subyugante". Este mismo premio fue otorgado a Rodrigo Burgos Cantor por su obra La ceiba de la memoria en el año 2009, al igual que a Ricardo Piglia con Blanco Nocturno en el 2012 y a Chico Buarque en el 2013 con la obra Leche derramada. ${ }^{4}$

De esta manera, tres instancias de indudable consagración en Latinoamérica otorgan la legitimidad literaria a Pablo Montoya. No solo uno sino tres reconocimientos en el transcurso de dos años aumentarán el grado de reconocimiento no solo a nivel nacional y latinoamericano, sino también fuera de América Latina, pues a partir de estas distinciones se dispara la contratación de las traducciones de la obra de Pablo Montoya. El escritor desconocido (o conocido solo para unos cuantos lectores especializados) en su propio país, de un momento a otro, es reconocido en Colombia y fuera de ella.

Es importante insistir en la base material de la obra construida por Pablo Montoya; si bien en-

\footnotetext{
$4 \quad$ Es de aclarar que, en el momento en que Pablo gana el premio Casa de las Américas en Narrativa también lo obtuvo otro docente de la Universidad de Antioquia en el nivel de ensayo: Pedro Agudelo Rendón. Estos escritores que han surgido de las periferias, acuden a la academia como instancia de legitimación y privilegian la crítica académica para su reconocimiento.
} 
tre 1996 y 2001 las obras de este escritor son más producto de la autopublicación (ediciones pagadas de su "propio bolsillo"), es innegable que tras su vinculación como profesor de planta en la Universidad de Antioquia, el escritor consigue una plataforma de independencia económica y de mayor capital simbólico que le permitirá arriesgarse más fácilmente a publicar obras que no buscan congraciarse con las modas editoriales o con reconocimientos carentes de prestigio literario. Estamos ante un escritor, docente, investigador y crítico literario, quien se diferencia así ostensiblemente de los otros escritores en los cuales prima la función de periodistas.

La publicación de obras con editoriales universitarias e independientes con algún grado de reconocimiento en el campo literario nacional, los premios y distinciones del ámbito académico, su trayectoria como académico y la elección de un tema que, desde un punto de vista crítico, sintetiza la historia del subcontinente latinoamericano (la Conquista) allanaron el camino hacia la consagración por parte de instancias de la región, respaldada por una obra que hace evidente su defensa de una autonomía ética y estética, y por la legitimación de instancias que, al provenir también del ámbito académico, no hacen más que ratificar esta autonomía como una posición dominante dentro del campo literario ${ }^{5}$.

\section{Relación de las etapas con las instancias de consagración}

Los procesos que se han abordado respecto a la institución literaria $^{6}$, hay que analizarlos en retrospectiva, pues la literatura hispanoamericana del Boom dejó un legado a los escritores posteriores. Estos escritores obtuvieron sus reconocimientos a partir de la distinción del valor estético y del compromiso con la defensa de una posición crítica frente a las formas de violencia contra el territorio latinoamericano; esta herencia reaparece en el caso de Pablo Montoya. Si en la época del Boom, los escritores fueron reconocidos y consagrados al mismo tiempo por la academia y por los medios de comunicación, en adelante, academia y mass media se separarían y actuarían como instancias de legitimación en ámbitos literarios con distintos niveles de capital simbólico; a partir de ese momento, el escritor debería debatirse entre ser reconocido por la academia o por las editoriales y los medios masivos de comunicación. En el caso de Montoya, el hecho de haber sido reconocido primero por la academia y por la crítica literaria especializada, hace que el despliegue massmediático que sigue al otorgamiento de los tres galardones no ponga en entredicho la calidad estética de su obra. ${ }^{7}$ De esta manera se comprueba que, pese a que hoy las instancias de legitimación son diversas, el respaldo de la academia y de la crítica literaria especializada siguen siendo determinantes en la consagración de un escritor; si bien esta puede provenir de la publicación en editoriales de gran prestigio o reconocimiento literario, de premios editoriales o de un despliegue en la prensa

5 Paula Marín, doctora en literatura, docente e investigadora en el área de la sociología de la literatura, escribiría en su artículo La sociología de literatura sobre el libro de Gisele Sapiro (2016) publicado por la revista La Palabra (2017), que no se puede desconocer que el mercado literario provee un espacio para reafirmar la autonomía pues le provee de una base económica, en el que los escritores luchan por creer en el valor de la literatura y del arte para la sociedad.

6 Dubois (2014) describe de la siguiente manera la dinámica de la institución basándose en la teoría de Pierre Bourdieu: Podemos deducir hasta el momento tres mecanismos de la dinámica institucional. En primer lugar, diremos que el autor que entra en el campo literario y en su juego de concurrencia está obligado a adaptar su estrategia de emergencia a la relación que se establece entre su capital cultural y el conjunto estructurado de posiciones en el campo, propias de los agentes, los géneros y las instancias de consagración. (p. 48).

$7 \quad$ La trayectoria de Pablo Montoya continuará en un gran número de entrevistas e invitaciones que tendrá que aceptar aunque manifieste no querer figurar como una vedet. Sus compromisos con la editorial Random House y los premios otorgados que le permitieron salir de su anonimato, lo ponen como protagonista de diversos eventos culturales y de otras cuantas distinciones: miembro Correspondiente de la Academia de la Lengua el 21 de noviembre de 2016, Hijo llustre por la Alcaldía de Barrancabermeja e invitado a la Mesa por la Excelencia Educativa; participación en el Foro 'SOS por el aire' de la Universidad de Antioquia. 
cultural, cuando así sucede puede ponerse en duda más fácilmente, a falta del respaldo del capital simbólico legítimo que solo parece otorgar la academia.

La herencia del boom en Pablo Montoya se percibe también en los discursos que ofreció al recibir los premios. En ellos, se identifica lo que plantea Dubois: "La literatura exige del escritor una inversión personal total en ciertas 'posturas' (vocación, llamado, compromiso) que implican la identificación y desempeño de un papel al interior de la institución literaria" (Dubois, 2014, p. 48). La postura asumida por Montoya se relaciona con su cuestionamiento del papel de la literatura y de la sociedad en América Latina; allí, ubicamos una función muy clara del escritor en la actualidad, según lo plantea Montoya:

¿Por qué me he preocupado por tres pintores en cierta medida desconocidos? ¿Por qué, en mis anteriores novelas, he puesto como protagonistas a un poeta romano libertino, a un fotógrafo francés obsesionado por la desnudez humana y a un naturalista neogranadino extraviado en las guerras de Independencia? La respuesta es sencilla: ¿porque todos ellos intentan crear? los unos pinturas, el otro poemas, el de más allá daguerrotipos y el último herbarios- en medio de ámbitos turbulentos y represivos. Porque creo que, como una antorcha, que está siempre a punto de apagarse, el arte es una de las maneras que existen para dignificar al hombre en su capacidad de resistencia y la más paradigmática para mostrar su deterioro.

Y la verdad es que, aún sorprendido por este inmenso reconocimiento, debo manifestar a los miembros del jurado, al Celarg y a los venezolanos mi entera gratitud. Su gesto, a la vez magnánimo y temerario, ya que se ha premiado a un escritor completamente desconocido en el panorama hispanoamericano, me conmueve y me honra. $\mathrm{Y}$ entiendo que el Rómulo Gallegos, el más prestigioso en la narrativa en lengua española, se le ha otorgado a un libro dueño de ciertas particularidades. Su fuerte vínculo entre investigación histórica e imaginativa recreación del pasado. Su factura estética que se la juega sin vacilaciones por los abrazos entre narración, ensayo y poesía. Un universo, en fin, que ha bebido de Alejo Carpentier, Pablo Neruda y Álvaro Mutis, mis maestros en los primeros años del aprendizaje literario; y de Augusto Roa Bastos, Juan José Saer y Manuel Mujica Láinez, otros guías fundamentales de los años de la madurez.

Mi obra, y así concluyo estas palabras, ha sido escrita desde hace más de veinte años desde una cierta periferia. La periferia que representan todas las ciudades colombianas que no son Bogotá. La periferia de mi condición de inmigrante latinoamericano en Europa. Tal coyuntura la ha lanzado a unas zonas de silencio que me han parecido ásperas pero también afortunadas. Distante de las ferias de las vanidades letradas, desdeñoso del poder cultural, el ocultamiento me ha brindado la coraza de la autonomía. He escrito y seguiré haciéndolo con la conciencia de que escribir, como decía Albert Camus, es un acto solitario y solidario. Sabiendo que mi atalaya está sembrada en el cotidiano ejercicio de la disidencia. Y teniendo en cuenta que la única responsabilidad que tiene el escritor con sus lectores, es decir, cuando se sienta ante el azaroso vacío de la página en blanco, es trazar de la mejor manera la escurridiza palabra. (Montoya, 2 de agosto de 2015 [Fragmentos del discurso de aceptación del Premio Rómulo Gallegos]).

Los fragmentos del discurso permiten entender la postura de Pablo Montoya con relación a la distancia con 'las vanidades letradas', que según el autor le brindan 'la coraza de la autonomía”. La novela histórica que catapulta a Pablo Montoya hacia la consagración, Tríptico de la infamia, le permite legitimar esta toma de posición.

\section{Desde los otros}

Los discursos literarios de la sociedad moderna han motivado a 
sociólogos literarios como Jacques Dubois (1978), Dominique Maingueneau $(1998,2004)$ y Jerome Meizoz (2007, 2011), a desarrollar un aparato conceptual para abordar el debate en torno a la construcción de la figura autorial, pues en ella no solo participa el autor, sino también agentes que conforman, de una manera u otra, el proceso de difusión y consagración; entre estos, se encuentran los editores, críticos, instituciones escolares y universitarias, etc. Encontrar las instancias que gestionan el discurso de Pablo Montoya, es encontrar a un autor que construye una distinción frente a otros autores dentro de la institución de la literatura colombiana. Pero, ¿qué agentes acompañan la imagen y postura que Pablo ha logrado establecer? ¿Cómo es reconocido en los medios? ¿Le reconocen como él quiere ser reconocido?

Las referencias a Pablo Montoya en los medios escritos, han ido en aumento desde el momento en que gana el Premio Rómulo Gallegos: artículos en revistas académicas (Revistas de literatura de la Universidad de Antioquía, La Universidad Nacional de Colombia, La UPTC de Tunja en la revista La Palabra, La Pontificia Universidad Javeriana, La Universidad de Los Andes), en revistas literarias (Número, Arcadia, Literariedad, Libros y letras, Común Presencia) y en algunas revistas internacionales (Universidad de la Rioja, la revista Persée de Francia o Aurora Boreal de Copenhague). Las revistas anteriores resaltan la labor de un autor cuyo fin es apostarle a la creación estética que enriquece con una mirada innovadora las letras colombianas. Los artículos hacen referencia, por otro lado, a las publicaciones hechas desde Tríptico de la infamia, como lo es Terceto (Random House 2016) y las reediciones de obras como Viajeros y Cuadernos de París, y a la presentación de estas obras y la obra en general de Pablo exaltando la influencia de las artes en su narrativa. En los periódicos, se puede rastrear su presencia desde 2008 cuando comienza a publicar novela (el género literario que le ha valido su consagración y al que aspiraba a llegar desde la escritura de sus primeros cuentos y poemas) y ha sido titular de los periódicos de distribución nacional, regional y periódicos internacionales en Latinoamérica y España, luego del premio Rómulo Gallegos; todos coinciden en registrar la noticia de un escritor "que hasta ahora permanecía en el anonimato" y en resaltarlo como "autor de culto", alejado de la 'frivolidad' de la literatura más comercial colombiana.

En España, el diario El Español publicó un artículo titulado "Pablo Montoya, el mejor escritor colombiano que España desprecia", en el cual se encuentra la siguiente entradilla: Pablo Montoya (Barrancabermeja, 1963) sabe cuál es el precio a pagar por ser escritor en Colombia y negarse a escribir sobre narcos y sicarios: la marginalidad (Maldonado, 7 de septiembre de 2016).

Por su parte, el periódico El País de España en su edición del 06 de junio de 2015, publica un artículo sobre Montoya con el titular "El Rómulo Gallegos consagra al colombiano Pablo Montoya", y en su contenido deja ver lo poco conocido que es el autor para los españoles: "Es un autor poco conocido porque no está inscrito en la tradición literaria vinculada al problema de la violencia, muy cultivada por los escritores de su país" (Sánchez, 06 de junio de 2015).

Publicaciones sobre Montoya son más frecuentes en revistas académicas y especializadas. La crítica literaria colombiana se acerca de manera respetuosa a sus obras. En el ámbito académico, ha sido bien recibido. La Universidad de Antioquia ha sido la que más ha publicado artículos de investigación sobre sus obras, que van desde el tópico literario colombiano, pasando por la música, hasta la representación de la violencia.

Escritores colombianos como Juan Manuel Roca, Piedad Bonnet, Roberto Burgos Cantor y Julio Paredes, han hecho valoraciones de sus obras. Los dos últimos aparecen en las con- 
traportadas de su libro El beso de la noche con las siguientes apreciaciones:

Este libro de cuentos, de cuidado rigor en el lenguaje, se acerca a las precisiones abiertas de la poesía y le ofrece al lector la inmersión en dos mundos cuya semejanza surge de la extrañeza, quizá de lo insólito pero posible, algo destella después de los logros autónomos de cada cuento. Roberto Burgos Cantor.

En los cuentos de El beso de la noche de Pablo Montoya el lector se encontrará con una voz poética inquietante y muy difícil de olvidar. Con las cualidades indiscutibles de la una verdadera literatura de autor, los presentes relatos nos llevan de la mano de una retórica impecable, no solo a los límites de la realidad cotidiana sino también a los de una fantasía con personajes que estremecen la imaginación de cualquiera. Julio Paredes.

Estos autores encuentran en el escritor Pablo Montoya, una riqueza literaria desde el mismo tratamiento de los temas de las obras, también se han interesado por los personajes en sus novelas históricas y sus críticas profundizan en contextualizar los personajes, artistas y fotógrafos, que fueron la fuente de Pablo para su creación. Los autores coinciden en esa mirada al pasado desde la perspectiva crítica de sus narraciones y el cambio de mirada del artista europeo sobre los habitantes del continente americano y los pueblos aborígenes. Nótese además, que en los testimonios de estos autores, la exaltación de la "prosa impecable" de Pablo Montoya, sus "logros autónomos" y las "cualidades indiscutibles de la una verdadera literatura de autor", todas son características, pues, de una literatura autónoma, distanciada de las modas y del interés económico dentro de la dinámica de la institución literaria.

Respecto a su producción ensayística, también ha sido bien recibido. Poco a poco, Pablo Montoya comienza a ser citado por la academia y luego consagrado también por ella (en el ámbito internacional). Dentro del modelo actual del escritor-periodista que parece imperar en el campo literario, según la percepción de muchos y del mismo Montoya, este logra 'imponer' su imagen de autor autónomo, en términos estéticos e ideológicos, luego de casi veinte años de trayectoria y de veinte obras publicadas. Así, Montoya establece una nueva postura de autor consagrado en Colombia, en el campo literario reciente: un escritor académi$\mathrm{co}^{8}$.

Esta forma en la que separa su creación literaria de los otros escritores (y sus premios de los de los otros), ha sido replicada en la crítica de divulgación cultural y se ha empezado a difundir hasta el punto de encontrar varios artículos con las mismas referencias al autor colombiano consagrado desde el principio autónomo de la literatura: "En el medio literario colombiano desde el realismo mágico o urbano, en medio del realismo sucio, me parece que puedo apostarle a propuestas más afincadas en lo artístico. En mis obras, invito al lector a adentrarse en un mundo en el que debe elegir si entra o no." (Montoya, Entrevista en Hoyos, 05 de julio de 2016).

La consagración de Pablo Montoya le abre el espacio en la Academia Colombiana de la Lengua como miembro Corres-

\footnotetext{
8 Juan Zapata hace aproximaciones a la literatura colombiana y a la postura del autor en su texto La invención del autor. Nuevas aproximaciones al estudio sociológico y discursivo de la figura autorial: "Un poeta maldito en Colombia" El caso de José Asunción Silva". Zapata analiza la postura del escritor maldito con todos su tópicos (la miseria, el desinterés, la persecución, la locura, el consumo de estimulantes) y escenas que construyen los mismos autores (el periplo bohemio en París, la visita al gran escritor, el retorno al país de origen, la consolidación de cenáculos vanguardistas y la creación de revistas, la agonía solitaria y el suicidio), ambos elementos esenciales en la batalla por la autonomización de las literaturas nacionales. Sin embargo, el mismo Montoya afirmaba (en la misma entrevista) el hecho de que eran las novelas más comerciales las que permitían que Random House pudiera publicar las de autores que no vendían tanto, es decir, confirmaba que la lógica literatura comercial vs. literatura autónoma era necesaria para el 'buen' funcionamiento del campo literario.
} 
pondiente. Su discurso fue publicado por diferentes medios de comunicación: "Español: Lengua mía”. Este hecho le reafirma en el campo literario autónomo; es un reconocimiento más hecho por una instancia consagradora, proveniente (al igual que los otros galardones) del ámbito académico, de gran peso aún en la institución literaria colombiana. Este reconocimiento se otorga a filósofos, políticos, literatos y personajes influyentes en la vida cultural de Colombia; la Academia fue fundada a finales del siglo XIX por reconocidos filólogos y literatos, como José María Vergara y Vergara, Miguel Antonio Caro, José Manuel Marroquín, Rufino José Cuervo, entre otros.

Desde la primera publicación a nivel nacional que aparece sobre la obra de Pablo Montoya (Magazín Dominical de El Espectador, 1998), es posible entender cómo un grupo de escritores, que no son reconocidos en el ámbito nacional pero sí regional y académico, lectores de las publicaciones de Montoya, resaltan la erudición, el cuidado por la estética, la hibridación de géneros en sus composiciones y la diversidad temática que acompaña su obra al finalizar el siglo XX.

La verdadera consagración es la que da el tiempo al escritor. Esos asuntos comercia- les públicos son interesantes porque forma parte de la vida del escritor, pero la obra literaria para que se consagre necesita la aceptación de varias generaciones de escritores [...]. Yo no sé qué va a pasar. Cuántos escritores del tiempo pasado fueron aclamados y hoy no se sabe nada de ellos, no los han releído porque se marchitó su obra9 9 .

Lo dicho hasta aquí no significa que la trayectoria de Montoya lo haya llevado de manera lógica a la consagración, pero sí que su persistencia en el campo literario por veinte años, la elección de los géneros literarios que aparecen en sus obras, la elección de sus temáticas y de su estilo, fueron las apuestas de su escritura, acompañadas de su decisión de presentar su obra a ciertos concursos y sus originales a ciertas editoriales, y de participar en ciertos eventos literarios que lo fueron dotando de un capital simbólico significativo. La publicación de su obra en editoriales como Alfaguara, Panamericana y Random House, y el otorgamiento de los premios Gallegos, Donoso y Arguedas, llegaron como una manera de extender su público lector y su reconocimiento, en un momento en el que ese capital simbólico construido no podía ser puesto en duda. Así, pues, se demuestra que, como lo plantea Dominique Maingueneau, "Un análisis del discurso literario está obligado a introducir ese tercero que es la institución, de contestar esas unidades ilusoriamente compactas que son el creador o la sociedad: no con el fin de debilitar la parte de la creación misma en nombre de los determinismos sociales, sino con el fin de reintegrar la obra a los territorios, a los ritos, a los roles que la hacen posible y que ella hace posibles" (Maingueneau en Zapata, 2014, p. 54).

A la par que la institución literaria funciona cada vez más con una lógica manejada por las grandes editoriales y por los grandes grupos dueños de los medios de comunicación, sigue existiendo otra lógica 'subterránea', menos visible, perceptible a través de las revistas que están en las provincias, de las pequeñas editoriales que publican poesía, cuento, ensayo, en las universidades, un universo literario palpitante del cual se conoce muy poco siempre y que va gestando, poco a poco, propuestas, autores, obras que continúan haciéndole el necesario contrapeso a esa otra lógica más comercial. El caso de Montoya así lo demuestra.

Por supuesto, lo expuesto en este artículo también deja varias puertas abiertas para seguir indagando en el caso de Pablo Montoya y en el de otros escritores colombianos contem-

$\overline{9} \quad$ En entrevista personal con la autora (abril de 2017). Pablo aclara cuál es el concepto de consagración para él mismo. 
poráneos. Esta es, apenas, una introducción que permitirá más adelante profundizar en el análisis de obras literarias específicas de Pablo Montoya, con el fin observar detalladamente el proceso literario de creación en este autor; asimismo, sería necesario poner a Montoya en relación con otros escritores del momento, sobre todo, aquellos que hoy también se instalan en el subgénero de la novela histórica, como Juan Gabriel Vásquez y William Ospina, solo por mencionar a los más conocidos.

\section{Referencias}

Bourdieu, P. (1990) El campo literario. Prerrequisitos críticos y principios de método.

La Habana, Cuba. En Criterios número 25-28. pp. 20-42.

Bourdieu, P. (1995). Las reglas del arte: Génesis y estructura del campo literario (trad. Thomas Kauf). Barcelona, España: Editorial Anagrama S.A.

Bourdieu, P. (2003). La producción de la creencia. Contribución a una economía de los bienes simbólicos. En Creencia artística y bienes simbólicos. Elementos para una sociología de la cultura (trad. Alicia Gutiérrez). Córdoba, Argentina: Aurelia Rivera. [Versión original] (1977) La Production de la croyance. Contribution à une économie des biens symboliques, en Actes de la recherche en sciences sociales, n¹3, febrero 1977, p. 5. (2007). El sentido práctico. Buenos Aires, Argentina: Siglo XXI Editores.

Bourdieu, P. (2012). Bosquejo de una teoría práctica. Buenos Aires, Argentina. Prometeo Editorial.

Castaño Guzmán, A. (06 de enero de 2016). Trabajar con autores desconocidos es hacer $\quad$ re s i s te $n$ cia social. Revista Arcadia.Recuperado de: http://postigodeorcasas.blogspot.com. co/2017/03/195-silaba-editores-y-lucia- donadio-en.html

Canon, valor y premios literarios (2017). Recuperado de: https://teorialiteraria2.files. wordpress.com/2016/08/de-diego-josc3a9-luis-canon- valor-y-premios-literarios.pdf

Centro de Estudios Latinoamericanos Rómulo Gallegos (CELARG), Venezuela, Caracas.

Web institucional: http://www.celarg.org.ve

Carrizosa, A. (21 de mayo de 2016). Pablo Montoya y la creación artística en los tiempos del horror. La Nación. Recuperado de: http://www.lanacion.com. ar/1897234-pablo-montoya-y-la-creacion-artistica-en-los- tiempos-del-horror

Dubois, J (1976). La institución de la literatura (trad. Juan Zapata). Medellín, Colombia: Editorial Universidad de Antioquia. 2014. 
Eagleton, T. (1998). Fenomenología, hermenéutica y teoría. En Una introducción a la teoría literaria ( $2^{\circ}$ ed) (trad. José Esteban Calderón) (pp.73-113). México D.F., México: Editorial Fondo de Cultura Económica.

Eco (1960-1984) y las dinámicas del campo literario colombiano de mitad del siglo XX. En Revista Lingüística y Literatura, Vol. 35, fasc. 66, pp 107- 126.

Eco (2014) “Las revistas Mito (1955-1962) y Letras Nacionales (1965-1985): dinámicas del campo literario colombiano de mitad del siglo XX" Utopías móviles. Nuevos caminos para la historia intelectual en América Latina. En Colombia (pp.118-143). Medellín, Colombia: ed. Diente de León.

Eco (2012) La novela colombiana reciente ante el mercado: críticos contra lectores. Los casos de Mario Mendoza, Jorge Franco y Santiago Gamboa. En Colombia literatura: teoría, historia, crítica, vol.14 fasc. n/a, pp. $17-49$.

Eco (2016). [Reseña del libro La invención del autor: nuevas aproximaciones al estudio sociológico y discursivo de la figura autorial, de J. Zapata]. En Estudios de literatura colombiana, 38, pp. 209-213. DOI: 10.17533/udea. elc.n38a11.

Escobar, H., Juliana, B. (julio-diciembre de 2017). Hacia una teoría sociocrítica del texto. Edmond Cros (traducción de Hernando Escobar y Juliana Borrero). La Palabra, (31), 29-38.

Fernandez, B. A. (2010) Introducción: elementos para una teoría del valor literario. En Dossier cuestiones de valor (pp. 7-22). Rosario, Argentina: Facultad de humanidades y artes Universidad del Rosario. Recuperado de: https://www.academia.edu/3481996/Dossier_Cuestiones_de_valor

Fuenmayor, M. (2013) [Reseña del libro Un Robinson cercano. Diez ensayos sobre literatura francesa del siglo $X X$. de Montoya, P.]. En Literatura: teoría, historia, crítica. Vol. 15, No. 2.

Guzmán Méndez, D.P., \& Marín Colorado, P.A. (julio-diciembre de 2016).Lectores y textos escolares durante la primera mitad del siglo XX en Colombia. La Palabra, (29), 185-197.

Huaman, M.A. (2007) Fundamentos de la investigación literaria. En Tesis, Revista de la Unidad de Post Grado de la Facultad de Letras y Ciencias Humanas de la UMNMSM, N 1.

Jiménez, D. (1992). Historia de la crítica literaria en Colombia. Siglos XIX y XX. Bogotá, Colombia: Universidad Nacional de Colombia.

Jurado, M (12 de septiembre de 2016). Pablo Montoya: exorcizando la violencia con literatura. La $\quad \mathrm{R} \mathrm{e} \mathrm{-}$ pública. Ecuador. Recuperado de http://www.larepublica.ec/blog/cultura/2016/09/12/pablo-montoya-exorcisando-la- violencia-con-literatura/

Mächler Tobar, E \& MONTOYA, P. (2012). Du combat à la contredanse: musique et indépendance en Colombie, circa 1810. En América: Cahiers du CRICCAL, Vol. 41, No. 1. pp. 89-102.

Marin, P (2017) [Reseña del libro de Sapiro Giséle (2016) La sociología de la literatura. Trad. Laura Fólica] En Revista La palabra, (31),191-195. 
Montoya, P (1996) Cuentos de Niquia (ed. Bilingüe). París, Francia, Vericuetos.

Montoya, P (2009). Novela histórica en Colombia, 1988-2008. Entre la pompa y el fracaso.

Medellín, Colombia: Editorial Universidad de Antioquia.

Montoya, P (2000) La representación de la violencia en la reciente literatura colombiana (década de 1990). En América: Cahiers du CRICCAL, Vol. 24, No. 1. pp. 49-55.

Montoya, P (2002). Rumba y fiesta en ¡Que Viva la Música! y Opio en las nubes. En América: Cahiers du CRICCAL, Vol. 28, No. 1. pp. 253-259.

Montoya, P (2014). Tríptico de la infamia. Medellín, Colombia: Editorial Random House.

Montoya, P (2013). Un Robinson cercano. Diez ensayos sobre literatura francesa del siglo XX. Medellín, Colombia: Fondo Editorial Universidad EAFIT.

Montoya, P (2012). Los derrotados. Medellín, Colombia: Sílaba.

Meizoz, J. (2015). Posturas literarias. Puestas en escena modernas del autor. Traducción y prólogo de Juan Zapata. Bogotá, Colombia: Ediciones Uniandes.

Muller y Grass (2015). América Latina y la literatura mundial. Mercado editorial, redes globales y la invención de un continente. Madrid/Franfurt: Editorial Iberoamericana - Editorial Vervuert.

Mckencie, D.F (2005). Bibliografia y sociología de los textos. Madrid, España: Akal ediciones.

Padilla, I. (2016). A propósito de Jacques Dubois y la traducción al castellano de su libro La institución de la literatura (1978). En Lit. Teor. Hist. Crit., Vol. 18, Número 1, pp. 195-208. Recuperado d e : http://www.revistas.unal.edu.co/index.php/lthc/article/view/54686/56040 [Accessed 20 Apr. 2017].

Pouliquen, H. (julio-diciembre de 2017). De la sociología de la literatura a la sociocrítica y a la estética sociológica. La Palabra, (31), 39-49.

Rodríguez, E. (2013). La lectura como acto vital e interpretativo. En ¿Lectores o leedores? (pp.31-53). Bogotá, Colombia: Universidad Nacional de Colombia.

Zapata, J (2011) Muerte y resurrección del autor. Nuevas aproximaciones al estudio sociológico del autor. En Lingüística y Literatura, No. 60. pp. 35-58.

(2012). Cómo analizar la posición social del intelectual en Colombia. En Revista Lingüistica y Literatura, Vol. 35, fasc. 62. pp 107-126.

(2014) La invención del autor; nuevas aproximaciones al estudio sociológico y discursivo de la figura autorial (comp. Juan Zapata). Medellín, Colombia: Editorial Universidad de Antioquia.

(2015) ¿Podemos hablar de una postura del traductor?. En Tropelías. Revista de Teoría de la Literatura y Literatura Comparada, 24. pp. 93-99. 